\title{
HUMAN RESOURCES DEPARTMENT ROLE IN EMPLOYEES TRAINING AND EDUCATION IN SERVICE SECTOR
}

\author{
Vilmoš Tot ${ }^{1}$ \\ Tijana Savić Tot ${ }^{2}$ \\ Sreto Aleksić ${ }^{3}$ (D)
}

DOI: https://doi.org/10.31410/tmt.2019.413

\begin{abstract}
Modern organizations are aware that their development to the greatest extent depends on the employees' education and they put all of their efforts in employing appropriate individuals as well as in providing the prerequisites to the employees for constant advancement of knowledge in order to have the organization's development as the consequence. Responsibility for the development of human resources is a priority for the entire organization from strategic to operational level. The task of the strategic level of management in organizations is to create a commitment to continuous improvement of employees' knowledge and skills and creation of basic preconditions for their development. The operational level implies the existence of a human resources department which, by constant monitoring of the work process, has a role to continuously develop and adapt human resources systems in accordance with the needs of the organization. Within this paper the results of the research will be presented on conditions the organizations in service sector on the territory of Novi Sad municipality provide during training and education of the employees as well as of peculiarities of the activities in relation to the bearers of responsibility for human resources in the organization.
\end{abstract}

Keywords: human resources development, employees training and education, human resources department.

\section{INTRODUCTORY CONSIDERATIONS}

$\mathrm{M}$ odern operations impose the need on organizations for finding ways and methods that will provide them the survival on the market. In the stable environment following the organizations till the beginning of the 80 -ties, the focus was directed on identifying the factors influencing and forming their business as well as the tools, methods and approaches which would provide as efficient utilization of the material resources as possible. The means the practitioners and theorists have designed today provide the functioning but do not guarantee an organization's survival, development and competitiveness. Even since the long past 1954. Drucker, P., (1954) announced the incoming of a society and employees of knowledge as the main development holders, Senge, P., (1990) affirmed the concept of learning organizations, Stewart, T., (1997) offered as a solution the concept of intellectual capital showing that the intensity of the ambient changes has as the consequence the development of new areas and practices of management dealing with the issues of managing the intangible properties. Organizations are searching for a faster answer in terms of methods, models, tools, practices and approaches that will provide them the market competitiveness. The common factor in all the concepts developing as the answer to the changes and as a condition of organizations' development are people.

Faculty of Information Technology and Engineering, Jurija Gagarina 149a, Belgrade, Serbia

Faculty of Management, Njegoševa 1a, Sremski Karlovci, Serbia

College of Professional Studies in Management and Business Communication, Modene 5, Novi Sad, Serbia 
The Human Resources field suffered numerous changes in the previous fifty years (Dyer, 1999., Rothstein, 1999). The very function of the resources has come a long way from personnel department wherein it had exclusively administrative role to the function of human resources management which finally admitted the legitimacy of people as the only inexhaustible and renewable resource that is also focused on development of practices, the purpose of which is directing individual skills, abilities and interests towards the organizational goals accomplishment. (Schuler, 1998). Nowadays, human resources are observed as a set of available talents of people as potential partners in creating and realization of organizational strategy (Schuler, Jackson, 2000). Employees today are aware of the fact that the organization's success depends on the quality of the available human resources; moreover, in many sectors of labor market there is a true war for the best individuals. Organizations reach the quality people by an adequate modeling of the elements of human resources management, namely by a quality and efficient planning, recruiting and selection you can come to the professionals that will be capable of performing successfully the tasks that certain posts require, that will have the appropriate conditions for development and that will be satisfied at their workplaces. In the context, human resources management applies a clear integrative approach providing the right people on the right places, in the right time with the appropriate competence and motivation for accomplishing the planned performances and develop their potential in the process of the company's growth and development.

For a long time, employees training and education as well as the function of the human resources management have been perceived as an expense and not as an investment; and reduction of labor force is still one of the main strategies of the expenses' decrease (Uchitelle, Kleinfield, 1996). The most comprising study on the influence of employees training and education on business results is certainly Hansson's, B., study (2001) in which he conducted the research in 6000 organizations in 26 different countries of Europe and proven their positive influence on fluctuation decrease, increase of performance, profit and growth of the stocks' price. Another significant research on the influence of training and education on organizations' operations is the research conducted on the territory of Great Britain (Tamkin, Campbell, Hillage, 2004), showing that investing into education of the employees by the gained profit overcomes the expenses per worker, that the more performable organizations employ more educated employees and that different types of training influence on improvement of various results. Numerous research over the years have shown that the practices in managing and development of human resources essentially influence on an organization's outputs (Miles, Snow, 1984., Schuler, Jackson, 1987., Lengnick-Hall, Lengnick-Hall, 1990., Baird, Meshoulam, 1988., Jackson, Schuler, Rivero, 1989., Wright, Snell, 1998., Jackson, Schuler, 1995. Wright, Smart, McMahan, 1995., Barney, Wright, 1998., Kepes, Delery, 2007., Shih, Chiang, Hsu, 2006) but also, that there still remains the problem of adjusting the practices to the conditions in which a company is operating and to the characteristics of the work force it disposes of.

The adjustment to the changeable circumstances and the readiness for learning and adopting new knowledge and skills become more important than the competencies for performing a certain job. The employees have to be prepared to respond to the problems and challenges they face with for the first time. Such an ambient influences on the system of education and educational institutions, on employees and employers and poses the necessity of promoting and creating the frames for implementation of the concept of training and education on workplace.

For an average employee additional training means promotion of the skills, job satisfaction and increase of its own values on labor market. The best response for the organizations to future challenges represent highly-educated and motivated workers. One of the ways the human re- 
sources department can contribute to creation of the competitive advantage is defining the program of training and education of employees for the purpose of creating the intellectual capital (Noe, et al., 2000)

The concept of developing education of both individuals, as members of society and of the employees as members of organization becomes one of the key factors for acquiring competitive advantage in today's economy of knowledge and a condition for organizations' survival. Developing human resources within an organization, educating and training at the workplace is one of the ways to achieve the goal. All of the data lead to the conclusion that organizations become the most important educating institutions of today.

Within this paper the results of the research will be presented on conditions the organizations on the territory of Novi Sad municipality provide during the employees training and education as well as of peculiarities of the conditions in relation to the responsibility bearers for human resources in the organization.

\section{TRAINING AND EDUCATION OF THE EMPLOYEES}

The purpose of trainings is acquiring new knowledge, skills and behaviors and their application in everyday operations. So that a company would gain competitive advantage, the training has to be directed not only on qualifying the employees for work on the current operations but also on development of their knowledge and skills in accordance with the strategic course of the organization's development which will, as the consequence, have creating and strengthening of the human capital. (Noe, 2001).

Training implies any learning activity directed towards acquiring specific knowledge and skills necessary for successful job or task performance. (Šiber, 1999.) The trainings would relate to the efficient and safe handling of some machine, improving skills for selling, presentations and similar. Whereas the trainings are oriented to the job, development is on the other hand directed towards the future requirements in terms of knowledge and skills aimed at the advancement and not on performance of the job. Development is primarily directed to future needs of an organization for human resources and only afterwards on developmental needs of an individual within the organization. Human resources department in most of the organizations is responsible for coordination of the activities related to the training and education of the employees because it has the best view of the importance of the employees' career development and the significance of development of the organization as a whole. On the other hand, managers are most probably the best source of the technical information necessary for acquiring skills as well as for decisions on when the employees have the need for training (Noe, 2001). Close cooperation and constant interaction between managers and the human resources department represents the winning combination in estimating the employees' developmental potentials. It has been estimated that the organizations in the USA spend 54 milliard dollars on their employees' education (Robbins, Coulter, 2005). Naturally, managers are responsible for the decisions on the type of training necessary for the employees, when it is necessary to them and what form should the training have.

The employees' training is an important activity of human resources development. An organization, as it has been mentioned, in today's ambient cannot afford itself to remain the same. It has to be prepared for changes, implying also that the employees have to be ready for the changes. Since the workplace requires changes, the employees' skills should be changed and adjusted to new demands of the workplace. 
All of the above mentioned leads us to the need of a systematic tracking and promotion of knowledge on the level of organization, wherein the following model of human resources development process in organizations can be helpful, containing the following elements (Šiber, 1999):

1. Determination of an organization's educating needs - the basic task of this phase is to determine what knowledge, skills and abilities the employees should possess for successful job performance and achievement of the organizational goals, what are the employees not having or having insufficient knowledge and skills and whether the education will solve the deficiencies. In order to answer these questions, it is necessary to conduct thorough analyses on three levels: the analysis of the organization, the analysis of the job and the analysis of the performer of the job, i.e. the individual.

a. the organization analysis provides general frame, course and needs for education. Aimed at determining the educational needs from the organization's perspective, its goals, business strategy, organizational units, culture, changes, resources and possibilities of education. In order to conduct the quality analysis of organization's educational needs it is necessary to include the analysis of human resources consisting of defining the human resources requirements, necessary skills and programs of their provision. In the human resources analysis for the purpose of determining the educational needs, the starting point is the following: the existing review of knowledge and skills, projection of needed knowledge and skills and the developmental component including forecasting of the employees' knowledge and skills according to the future courses of the organization's development.

b. the job analysis can be defined as "a process of collecting relevant information on business and specifying knowledge, capabilities, skills and other requirements necessary for a concrete job performance" (Schuler, 1995). The job analysis results are job descriptions and workplaces specification, the function of which is a detailed description of the tasks included in the job, establishing the connections and relations the job has with other jobs and determining the knowledge, skills and abilities the employee has to have in order to successfully perform the job.

c. the analysis of an individual provides the answer to the question to whom the education is needed for as well as what is the knowledge that would be the subject of the development. The basis for determining an individual's educational needs represents the analysis of compatibility of the needed and available knowledge, skills and abilities for performing a certain job. The education of individual is necessary at the change of working requirements, change of technology, change of standards, etc. The information on to whom the additional education is needed can be collected from numerous sources: the objective data (on the performance, quality of work, rejects, stoppages in production, absenteeism, fluctuation, accidents at work, etc.), estimation of the work success, annual plans of development, opinions and suggestions of the managers, opinions and suggestions of the employees, plans of career development, centers of estimation of the individual potentials, outgoing interviews, etc.

2. determination of the education goals - The goals represent a starting point for conceiving the educational programs but also a foundation for determining the criteria of the success estimation. Within an organization it can be observed general and special goals of education. General goals of education are (Katz, 1974):

a) enhancing the organization's competitive capacity,

b) improvement of the employees' performance, 
c) actualizing the employees' knowledge and skills,

d) avoidance of the managerial obsolescence,

e) solving the organizational problems,

f) directing of the newly-employed,

g) satisfying the individual growth needs.

Special goals of education are directed to the segment of behavior or areas of working successfulness that should be changed or advanced. Frequent special goals of the organizations are: improvement of the relationship with the consumers, changing attitudes, enhancing the team work skills, a more efficient time management, increase of work security, decreasing labor costs, increasing the capacities for solving the problems, etc. All the special goals are necessary to be accorded with different educational needs, groups and programs. They can be determined in terms of behavior or results that should be accomplished.

3. determination of education contents and program - the contents and programs of education are associated with the needs and goals they result from. Several levels and types of educational needs determining the specific contents of certain education programs occur in organizations.

4. The first level is aimed at training the employees for the actual business and removal of the gap between the expected and real successfulness usually originating as the consequence of discord between the work requirements and the educational profile of the performer. The second level of educational needs is associated with broadening individuals' knowledge and therewith also the increase of possibilities of performing more complex and various operations within the same organizational level. The third level of organizational needs is related to individual development of career, realization of succession plans and similar, namely to the preparation of the employees for performing more complex and demanding jobs. The fourth level of educational needs relates to the future. It includes the programs of education and specialization founded on the predicted outlook of needed knowledge and skills for the purpose of a certain strategy realization. Each level of educational needs sets different requirements in view of educational programs and contents.

While the levels of educational needs point to the intensity and depth of the needed education, the types of educational needs point to the contents, namely to the skills and knowledge that should be aimed at. Based on Katz's categorization of skills and knowledge within organization it can be can categorized four kinds of educational needs (Katz, 1974):

a) basic knowledge and skills (modern jobs are increasingly requiring a higher level of skills often lacking to the new employees, but also to those with longer years of service, for example mathematics, fast reading, orthography and similar. Numerous companies have perceived the need for development of basic skills and accordingly apply programs of enhancing general knowledge of their employees.

b) technical, vocational skills (including special knowledge, techniques, methods, procedures and similar often required for successful performance of some specific job. These skills are related to a specific job or vocation. Also, within them there is a need for constant improvement in actualizing the knowledge. 
c) interpersonal skills (including communication, interpersonal relationships, leading, labor relations, etc.)

d) conceptual, strategic skills (the skills of strategic and operative planning, forming of organization, establishing the policy, adaptation to changeable environment, etc.). These skills are most often a part of educational needs of medium and top-level managers).

Different categories of educational needs demand special programs, and also the decision in what way to satisfy them within or outside of the organization. In general, there are two types of programs: the programs of education at the workplace and programs of education outside the workplace that can be divided into two categories: the one happening in the company and outside the company, namely at faculties or education centers. The type of education program will depend, as already mentioned, on the level and type of educational needs, namely on the part of education related to the conceptual, strategic and interpersonal skills but also the specific, specially developing vocational skills and knowledge demand educational programs provided by faculties or other educating institutions. The essence of this phase is that organizations based on general rules and principles, establish the educational needs, goals and programs of education as well as the means of their realization and target groups aimed at.

5. selection of methods and techniques of education - Different methods are associated with specific goals and programs of training and education. Generally, all methods can be divided in two groups, namely, the methods of education at the workplace and methods of education outside the workplace.

a. The methods of education at the workplace - The importance of education at the workplace is also confirmed by great investments of companies in this activity. It is necessary for the newly-employed but also for the experienced workers during changes in technology, operating procedures and standards. The organizations applying this aspect of education have to define clearly the policy but also to specify the responsibility for conducting the policy. The methods of education at the workplace include: individual instructions, job rotation, vocational practice, training period, mentoring and students practice. The advantages of education at the workplace are the connection and direct applicability of the learned in performing a job, cost savings, continuity in work and other, whereas the disadvantages are lower quality of work, possibility of damaging the equipment, problems of the people doing the training and similar. Actually, it is often forgotten that the one doing a job well does not also have to know to transfer the knowledge in training others, meaning that the people performing the training should be carefully chosen.

b. the methods of education outside the workplace - Included in the methods of education outside the workplace are lectures, audio-visual techniques, programmed learning, computer aided learning, interactive video, conferences and discussions, simulations, methods of cases, role play, business games, etc.

The selection of an appropriate method depends on the educational program and the goals. The key question is what should be learned. The most compatible method has to fulfill the following (Cascio, op.cit., 375): starters' motivation for job promotion, clear illustration of desired skills and knowledge, active participation, practicing capacity, providing feedback information on the 
course of learning, the material structured from easier to heavier tasks, adaptation to specific problems, possibility of transfer of the learned into other situations. The researches show (Carroll, Paine, Ivancevich, 1972) that some methods are more efficient in acquiring knowledge and some at changing the attitudes for upraising the skills of solving problems, etc.

6. educational programs' evaluation - represents the final phase in the process of education and development of educational problems in which it is checked to what extents have the set educational goals been realized. In principle, the educational programs' evaluation has two purposes: to determine whether the program has reached its goals and whether it has come to the transfer of the learned into work, namely to the change of the work behavior and success and to determine the quality of organization, contents and realization of the programs for further advancement.

\section{RESEARCH RESULTS}

The paper's problem is to determine to what extent the economic subjects in service sector have recognized the need for training and education of their employees, as the important strategic element of creating competitive advantage and the most cost-effective investment.

The research hypothesis is:

- that there is a difference in training and education of employees in relation to bearers of responsibility for human resources (general manager, human resources department, human resources agency, legal department, no one).

The paper's goals:

- Determining whether the observed organizations have the human resources department,

- Determining the responsibility for human resources in the observed organizations,

- Investigating the spread of the activities of human resources management from the point of view of training and education in the observed organizations,

- Examine whether the need for permanent education and training is recognized from the point of view of the examinees themselves,

- Examining the level of job satisfaction and degree of utilization of examinees' potentials in the observed organizations.

In this research a questionnaire is used as a method of examination, conceived on the basis of reference analysis in the theoretical part of the paper. The very questionnaire is focused on examining the employees on the territory of Novi Sad is designed with questions related to the examinees' demographic characteristics as well as with a set of dependable variables and accumulation of questions related to the problems of training and education from the organizational aspect. From the statistical methods the analysis of frequency and crosstab analysis have been used. The results are processed in the statistics package SPSS. The instrument is designed for the needs of the research in accordance with the paper's goals and hypothesis.

The questionnaire consists of 27 questions of overt and covert type, the questions that besides circling the answer have a possibility of adding the replies and scales in which the examinees by circling one of the offered alternatives express the level of acceptance or refusal of the question's contents. 
The total number of examinees is 170 , employed in 120 different economic subjects in service sector on the territory of Novi Sad. The selection of organizations is made on the basis of random sample and on geographical attachment to the territory of Novi Sad wherein the research has been conducted. The questionnaires have been submitted to the employees in written forms. Anonymity has been secured for all of the examinees, and of personal data the name of the company, qualification, age, total length of years of service and name of the job currently performed by them has been asked. The examinees have been filling the questionnaire independently with the predicted time up to 30 minutes.

It should be emphasized that the obtained results do not have to represent objective indices in all the cases, but are based on individual estimates of the employees.

The answers of the examinees from the questionnaire have been processed, as needed, and in relation to the dependent variables: gender, form of the company (private, public and shareholding), vocation, age, years of service, existence of human resources department and bearers of responsibility for human resources activities in the organization.

Within the paper the research results will be presented in relation to the bearers of responsibility for human resources activities (general manager, human resources department, human resources agency, legal department, no one (under which the examinees implied the companies' owners which are also the managers) and someone else (managers of departments) in order to determine the eventual particularities and differences in training and education of the employees.

In order to check to what extent in the very systematization is the need for the function of human resources recognized, it has been checked whether the human resources department exists at all. In (47,3\%) of the organizations there is human resources department, in $(45 \%)$ of the organizations there is no such department and (7,7\%) of the examinees replied with 'I do not know'. In today's doing business when the human resources department is a necessity, the results in our ambient are still at a low level. The need for the department having a role of a strategic character in managing an organization, unfortunately, is still not recognized.

In the examined organizations the responsibility and works related to the employees is taken over by the general manager $(39,1 \%)$, human resources department $(35,5 \%)$, human resources agency $(0.6 \%)$, legal department $(11,8 \%)$, no one $(6.5 \%)$ and someone else $(5,9 \%)$. The domination of general manager as someone eventually deciding is not surprising when it is about activities in connection with human resources, which, on the other hand, speaks on a still centralized system and high level of autocracy. Since a very small number of organizations has participated in the research $(0,6 \%)$ in which the human resources agency is the bearer of the activities related to the employees, they will be shown within the results of the research but will not be included into the discussion due to the size of the sample which is inadequate for defining the conclusions.

Regarding bearer of responsibility for human resources in relation to the company's activity, in private companies it is the general manager $(48,1 \%)$, human resources department $(24,7 \%)$, human resources agency $(1,3 \%)$, legal department $(3,9 \%)$, no one $(10,4 \%)$ and $11,7 \%$ of the examinees replied someone else; in public companies the responsibility is taken by the general manager (35,2\%), human resources department (39,4\%), legal department $(19,7 \%)$, no one $(4,2 \%)$ and someone else $(1,4 \%)$; and in the stock holding companies the responsibility is taken 
by the general manager $(21,1 \%)$, human resources department $(68,4 \%)$ and legal department $(10,5 \%)$. As it is noticeable, the general manager domination is indisputable in private companies; a somewhat better situation is in the share holding companies wherein the domination of human resources department is evident. The domination of general manager in private companies can be the consequence of a still undivided ownership and managerial role, namely in the large number of organizations the owners themselves are in the function of general managers.

In organizations wherein there is the human resources department the responsibility and the operations related to the employees is taken over by the general manager $(15 \%)$, human resources department (73,8\%), legal department (10\%), and someone else $(1,3 \%)$.

The first task of an organization from the aspect of human resources and falling into the process of job analysis is to clearly define the jobs' descriptions that are the basis for following and development of the employees' skills but also a tool for the performances and output estimation of the employees. By the question whether there are descriptions of jobs in their organizations the goal was to find out whether the organizations have the basic tool in the human resources management process. In the total sample in $(78,7 \%)$ of the investigated organizations there are workplaces descriptions, in $(20,1 \%)$ of the organizations there are not and $(1,2 \%)$ of the examinees replied that they didn't know. In organizations wherein the general manager takes over the responsibility for human resources, there are workplaces descriptions $(74,2 \%)$, in $(25,8 \%)$ there are no such descriptions and no one of the examinees replied 'I do not know', in the organizations where there is the human resources department, the workplaces descriptions exist $(88,3 \%)$, do not exist (10\%) and 1,7\% of the examinees replied 'I do not know'; in the organizations wherein the legal department takes care of the employees the workplaces descriptions exist (85\%), do not exist (10\%) and 5\% of the examinees replied 'I do not know'; in the organizations wherein no one is in charge of the concern on the employees, the workplaces descriptions exist $(63,3 \%)$, do not exist (36,4\%); and in the organizations where the examinees responded that someone else is in charge of taking care of the employees the workplaces descriptions exist (50\%) and do not exist (50\%). According to the shown results, it can be concluded that the non-existence of the workplaces descriptions is alarming in even $50 \%$ of the organizations wherein in charged for human resources is someone else, namely the managers of departments and that they lack the education in human resources area and that they unwillingly delegate the responsibility related to people.

Whether there are deviations from what is defined in the jobs' descriptions and what the employees really do, it was checked with the question how much did the job descriptions corresponded to what they really did. In the total sample $(61,3 \%)$ of the examinees considers that the job descriptions correspond, $(36,3 \%)$ hold that they do not correspond and $(2,4 \%)$ replied 'I do not know'. Regardless of the fact that most of the examinees answered that the workplaces' descriptions correspond to what they do, the number of examinees considering that the job descriptions do not correspond to what they do is not negligible, if we take into consideration that job descriptions represent the basic tool for recruiting, selection, human resources development as well as for setting the goals, defining the training program, performance estimate, etc. From the aspect of human resources responsibility bearer: in the organizations wherein the general manager takes over the responsibility for human resources, the workplaces descriptions correspond to what the employees do $(66,2 \%)$, do not correspond $(32,3 \%)$ and $(1,5 \%)$ of the examinees replied 'I do not know'; in the organizations where the human resources department assumes the responsibility for human resources, the job descriptions correspond to what the employees do $(58,3 \%)$, do not correspond (40\%) and 1,7\% of the examinees replied 'I do not know'; in the organizations 
wherein the human resources agency takes on the responsibility for human resources, the job descriptions correspond to what the employees do (100\%); in the organizations wherein the legal department takes on the responsibility for human resources the job descriptions correspond to what the employees do (65\%), do not correspond (35\%) and no one of the examinees replied 'I do not know'; in organizations wherein no one is responsible for human resources, the job descriptions correspond to what the employees do (27,3\%), do not correspond (54,5\%) and 18,2\% of the examinees replied 'I do not know'; in the organizations where someone else takes on the responsibility for human resources, the job descriptions correspond to what the employees do (70\%), do not correspond (30\%) and no one of the examinees replied 'I do not know'.

It is interesting to notice that in the organizations in which there is the human resources department, the job descriptions do not correspond to what the employees actually do (40\%), which leads us to the presupposition that the work analysis has not been done well regardless of the fact that in $88,3 \%$ of the organizations there are jobs' descriptions or that the employees in the department are not competent in the area. It is also interesting to notice that in the organizations wherein someone else is taking on the responsibility for human resources, the job descriptions correspond with $70 \%$, leading us to the presupposition that such organizations have probably engaged specialized human resources agencies during their operations or that they have in-line managers that are well conversant with the activities of the work analysis.

Since the role of the employees' performance estimate is multiple, next goal was to examine the status in our organizations. In the total sample there are formal processes of the performance estimate $(48,3 \%)$, there are no formal processes of the performance estimation $(43,2 \%)$ and $(8,3 \%)$ of the examinees replied 'I do not know'. In the organizations wherein the general manager is responsible for human resources, there are formal processes of the performance estimation (37,9\%), there are not (47\%) and 15,2\% of the examinees replied 'I do not know'; in the organizations where the human resources department takes on the responsibility for human resources, the formal processes of the performance estimation exist (75\%), do not exist (20\%) and 5\% of the examinees replied 'I do not know'; in the organizations wherein the agency for human resources takes on the responsibility for human resources the formal processes of the performance estimate exist (100\%); in the organizations wherein the responsibility for human resources is taken on by the legal department the formal processes of the performance estimate exist (30\%\%), do not exist (65\%) and 5\% of the examinees replied 'I do not know'; in the organizations wherein no one takes on the responsibility for human resources, the formal processes of the performance estimation exist $(9,1 \%)$, do not exist (90,9\%); and no one of the examinees replied 'I do not know'; in the organizations wherein someone else takes on the responsibility for human resources the formal processes of the performance estimation exist (30\%), do not exist (70\%) and no one of the examinees replied 'I do not know'. Apart from the organization wherein the bearer of human resources responsibility is the human resources department, the formal processes of the performance estimation in most of the organizations do not exist. The purpose of the performance estimation is multiple. Based on the performance estimate the salary level, salaries' increase, advancement, transferal, allocation to lower level workplaces and dismissals are determined. The estimate assists in identifying the employees' education and improvement. Owing to the performance estimate, the employees are enabled to track how successful they are and to what extent they realize the results expected from them. Out of these reasons the formal procedure of the estimation well lead to the removal of subjective impressions of the one estimating (for example, the manager) and also, to a large extent, enables including a large number of criteria during the estimation in order to acquire an objective image on possibilities of each 
individual employee. The manager has to contact the employees because even the best employees can achieve the wanted results only if they know the concrete goals, and the management can settle their devotion only if having clear criteria and expectations and if he/she conveys it to the employees precisely. Also, the employee has to be informed on the estimate results in order to know to what extent he/she realized what is expected from him/her. Management based on the results and their natural continuation - reward per performance, become the essence of modern approach to management.

Regarding the periodical evaluation of the employees increasingly taking over the high position in operating plans of the management, it was interesting to find out the performance estimate frequency in our companies. In the total sample the estimate performance is held in a month $(1,8 \%)$, three months $(19,5 \%)$, six months $(7,3 \%)$, a year $(15,2 \%)$, randomly $(30,5 \%)$ and is not held at all $(25,6 \%)$; from the aspect of the responsibility bearer for human resources, in the organizations wherein the responsibility for the employees is taken on by the general manager, the performance estimate is held in a month $(1,6 \%)$, three months $(17,2 \%)$, six months $(6,3 \%)$, a year $(14,1 \%)$, randomly $(29,7 \%)$ and is not held at all $(31,3 \%)$; in the organizations wherein the responsibility for the employees is taken on by the human resources department, the performance estimate is held in a month $(1,7 \%)$, three months $(27,6 \%)$, six months $(12,1 \%)$, a year $(20,7 \%)$, randomly $(29,3 \%)$ and is not held at all $(8,6 \%)$; in the organizations wherein the responsibility for the employees is taken on by the agency for human resources, the estimate performance is held in three months $(21,1 \%)$, six months $(5,3 \%)$, randomly $(42,1 \%)$ and is not held at all $(26,3 \%)$; in the organizations where no one takes on the responsibility for the employees, the performance estimate is held in a year $(18,2 \%)$, randomly $(18,2 \%)$ and is not held at all $(63,6 \%)$; in the organizations where the responsibility for the employees is taken on by someone else, the performance estimate is held in a month (10\%), three months $(10 \%)$, a year (10\%), randomly $(30 \%)$ and is not held at all (40\%); on the basis of the shown results, it can be seen that the performance estimate in most of the organizations is held randomly based on which the system of advancement could be taken into question, transferal, rewarding, etc. It is also interesting that in the organizations $(29,3 \%)$ wherein the bearer of responsibility for the employees is human resources department, the performance estimate is random, pointing us to the possibilities of incompetence of the department in its work, incompetence of the employed in the department, etc.

As it has already been stated in the employees' work estimate the human resources department should be included, the manager of the department where the employee works and the directly superior should be included because they represent the team of people that can, to the best extent, define the requirements, skills, abilities and behavior necessary to the employees for certain job so that thereby they are the most competent for an objective estimate performance. In the total sample, the employees' work is estimated by the sector manager (34,1\%), direct superior $(53,9 \%)$, human resources department $(1,2 \%)$, someone else $(10,8 \%)$; from the aspect of the responsibility bearer for human resources: In the organizations wherein the human resources responsibility is taken on by the general manager, the employees' work is estimated by the sector manager $(41,5 \%)$, direct superior $(44,6 \%)$, human resources department $(1,5 \%)$, someone else $(12,3 \%)$; in the organizations wherein the responsibility for human resources is taken on by the human resources department, the employees' work is estimated by the sector manager $(36,7 \%)$, direct superior $(58,3 \%)$, human resources department $(1,7 \%)$, someone else $(3,3 \%)$; in the organizations wherein the responsibility for the human resources is taken on by the human resources agency, the employees work is estimated by the direct superior (100\%); in the organizations wherein the responsibility for human resources is taken on by the legal department, the employees' work is estimated 
by the sectors manager $(25 \%)$, direct superior $(70 \%)$, someone else $(5 \%)$; in the organizations wherein no one takes on the responsibility for human resources, the employees' work is estimated by the sectors manager $(9,1 \%)$, direct superior $(63,6 \%)$, someone else $(5 \%)$; in the organizations wherein the responsibility for human resources is taken on by someone else, the employees' work is estimated by the sectors manager $(22,2 \%)$, direct superior $(44,4 \%)$, someone else $(33,3 \%)$; The results show that in most of the examined organizations the employees' performance is estimated by the department manager and direct superior and that the participation of the human resources department is really small even in the organizations wherein it is the bearer of the operations related to people, fortifying the presupposition on human resources department incompetence in the organizations and disables the systematic tracking and development of the employees. Tracking the employees' performance exclusively by the direct superiors and departments' managers will surely not completely provide the objective image on the employees' performance.

A reward system can be observed in a narrow and broad sense (Bogićević Milkić, 2006) In the narrow sense, the reward system includes money, goods, status and/or services provided by the employer to the employees in exchange of the put in work, whereas in the broad sense it includes also the system for the employees' performance estimate since, besides the developmental purpose, the estimates can have an important role in determining the salaries, salaries increases and different types of incentives as well. The basic role of the reward system in an organization is to bring into accord the individual interests of the employees and the strategic goals of the company through attracting and keeping capable people, encouraging the employees to develop their abilities and knowledge, motivation of the employees and creation of the culture wherein the employees care for the success of the company they work in. By the question how satisfied they are and whether there is the reward system at all for the employees, the focus was to find out whether the organizations use the reward system as a tool in their business operations. In the total sample, the employees are completely satisfied with the reward system (13,1\%), partially satisfied (31\%), dissatisfied $(23,2 \%)$ and $32,7 \%$ of the examinees replied that there was no reward system; from the aspect of bearer of responsibility for human resources in the organizations wherein the responsibility for human resources is taken on by the general manager, the employees are completely satisfied with the reward system $(12,3 \%)$, partially satisfied $(27,7 \%)$, dissatisfied $(18,5 \%)$ and $41,5 \%$ of the examinees replied that there was no reward system; in the organizations wherein the responsibility for human resources is taken on by the human resources department, the employees are completely satisfied with the reward system (18,3\%), partially satisfied $(38,3 \%)$, dissatisfied $(27,6 \%)$ and $16,7 \%$ of the examinees replied that there was no reward system; in the organizations wherein the responsibility for human resources is taken on by the agency for human resources, $100 \%$ of the examinees answered that there was no reward system. In the organizations wherein the responsibility for human resources is taken on by the legal department none of the employees is completely satisfied, partially satisfied are (30\%), dissatisfied (25\%) and $40 \%$ of the examinees replied that the reward system did not exist; In the organizations where no one takes on the responsibility for human resources, the employees are completely satisfied with the reward system $(9,1 \%)$, partially satisfied $(9,1 \%)$, dissatisfied $(36,4 \%)$ and $45,5 \%$ of the examinees replied that there was no reward system; in the organizations where someone else takes on the responsibility for human resources, the employees are completely satisfied with the reward system (20\%), partially satisfied (30\%), dissatisfied (20\%) and $30 \%$ of the examinees replied that there was no reward system;

The results show an expressed dissatisfaction of the employees with the existing reward systems and a great percentage of the organizations wherein it does not exist at all. The differences 
between the bearer of responsibility for human resources are small but it is noticeable that in the organizations where the human resources department runs the operations related to the employees there are the most satisfied ones $(18,3 \%)$ and partially satisfied $(38,3 \%)$ with the existing reward system.

It was also interesting to investigate whether earnings, as a basic element of the reward system, in accordance with the results of the work, namely are the employees clear with what are the activities and behaviors the organization is valuing. In the total sample, a great dissatisfaction is expressed by the accordance of the earnings with the work outputs with 53,3\% of the dissatisfied examinees, $38,5 \%$ satisfied and $8,3 \%$ of the examinees that answered 'I do not know'. From the aspect of human resources responsibility bearer: In the organizations where the responsibility for human resources is taken on by the general manager, the earnings are in accordance with the work outputs $(40,9 \%)$, not in accordance with the work outputs $(50 \%)$ and 9,1\% of the examinees answered that they did not know; In the organizations where the responsibility for human resources is taken on by the human resources department, the earnings are in accordance with the work outputs $(43,3 \%)$, not in accordance with the work outputs (45\%) and 11,7\% of the examinees answered that they did not know; In the organizations where the responsibility for human resources is taken on by the human resources agency, the earnings are in accordance with the work outputs (100\%); In the organizations where the responsibility for human resources is taken on by the legal department, the earnings are in accordance with the work outputs (20\%), not in accordance with the work outputs ( $80 \%$ ) and no one of the examinees replied 'I do not know'; In the organizations where no one takes on the responsibility for human resources, the earnings are in accordance with the work outputs $(18,2 \%)$, not in accordance with the work outputs $(72,7 \%)$ and 9,1\% of the examinees replied 'I do not know'; In the organizations where someone else takes on the responsibility for human resources, the earnings are in accordance with the work outputs $(40 \%)$, not in accordance with the work $(60 \%)$ and none of the examinees answered 'I do not know'; The results show that in most of the organizations the earnings are not accordant to the work outputs which leads us to the presupposition that the existing reward systems, although in a small number of organizations, are wrongly defined. The most expressive discrepancy between the earnings and work outputs is in the organizations where the responsibility for human resources is taken on by the legal department, someone else and in the organizations where no one is responsible for the employees.

As it has already been mentioned, the training and education of human resources in today's ambient are not perceived as the expense but as the investment into the future and for that purpose it was important to check how many organizations in our ambient organize the employees' training and advancement at all. In the total sample, the trainings and advancements are organized in $57,4 \%$ of the organizations, are not organized in $33,7 \%$ of the organizations and $8,9 \%$ of the examinees replied 'I do not know'. From the aspect of human resources responsibility bearer: The trainings and development in the organizations wherein the general manager takes care of the employees are being organized (43,9\%), are not being organized (45,5\%) and 10,6\% of the examinees replied 'I do not know'; in the organizations wherein the human resources department takes care of the employees, the trainings and development are being organized (80\%), not being organized (13,3\%) and 6,7\% of the examinees replied 'I do not know'; in the organizations wherein the human resources agency takes care of the employees, the trainings and development are being organized (100\%); in the organizations wherein the legal department takes care of the employees (55\%), are not being organized (25\%) and $20 \%$ of the examinees replied 'I do not know'; in the organizations wherein no one takes care of the employees, the 
trainings and development are being organized (27,3\%), not being organized (72,7\%) and none of the examinees replied 'I do not know'; in the organizations wherein someone else takes care of the employees, the training and advancements are being organized $(40 \%)$, are not being organized (60\%) and none of the examinees replied 'I do not know'; According to the research results it can be noted that in the organizations with the human resources department $(80 \%)$ the need for improvement of the employees is mostly recognized, which is not the case with the organizations wherein the care on the employees is taken by the general manager, legal department, someone else (co-owners, managers) and wherein there are no bearers of activities related to people.

Having in mind the intensity of changes influencing on operations, it was interesting to check how often do organizations organize training and improvement of their employees. In the total sample, again, dominant is the result showing that in our organizations training and improvement are not being organized $(42,6 \%)$ and from organizations that are organizing them the greatest percentage $(24,3)$ are doing it in the period of six months. From the aspect of responsibility for human resources: In the organizations in which the general manager is responsible for human resources, the employees had the training in the past six months $(19,7 \%)$, during a year $(10,6 \%)$, three years $(16,7 \%)$ and have never had the training $(53 \%)$; in the organizations in which the human resources department is responsible for human resources, the employees had the training in the past six months $(37,7 \%)$, during a year $(18,6 \%)$, in three years $(13,6 \%)$ and have never had the training (30,5\%); in the organizations in which the agency for human resources is responsible for human resources, the employees had the training in three years $(100 \%)$; in the organizations in which the legal department is responsible for human resources, the employees had the training in the past six months $(5,3 \%)$, a year $(21,1 \%)$, three years $(36,8 \%)$ and have never had the training (36,8\%); in the organizations in which no one is responsible for human resources, the employees had the training in the past six months $(9,1 \%)$, a year $(18,2 \%)$, three years $(9,1 \%)$ and have never had the training $(63,6 \%)$; in the organizations in which someone else is responsible for human resources, the employees had the training in the past six months (30\%), three years (20\%) and have never had the training (50\%); In the answers of the examinees still dominating is the standpoint that the trainings are not being organized, however in the organizations wherein the bearer of activities related to the employees is the human resources department, observable is the drift and the trainings are most frequently organized in the period of six months, whereas in the organizations in which the bearer of activities related to the employees is the legal department, the most frequent organization of the training is in the period of three years.

The training at beginning of employment has had a half of the examinees $(50 \%)$ in the total sample. From the aspect of human resources responsibility bearer in the organizations in which the general manager takes care of the employees, the training at the employment had $(38,5 \%)$ of the examinees and did not have (61,5\%); in the organizations wherein in charge of the employees is the human resources department, the training at employment had $(64,4 \%)$ of the examinees and did not have $(35,6 \%)$ of the examinees; in the organizations wherein in charge of the employees is the human resources agency, the training at the employment had $(100 \%)$; in the organizations wherein in charge of the employees is the legal department, the training at the employment had (40\%) of the examinees and did not have $(60 \%)$ of the examinees; in the organizations wherein no one is in charge of the employees, the training at the employment had $(60 \%)$ of the examinees and did not have $(40 \%)$ of the examinees; in the organizations wherein in charge of the employees is someone else, the training at the employment had (40\%) of the 
examinees and did not have $(60 \%)$ of the examinees; It can be noticed that the training at the employment is dominant at the organizations in which in charge of the employees is the human resources department. On the other hand, it is highly surprising that in the organizations in which no one is in charge of human resources also dominant is the training at the employment.

Additional training for the job they perform in the total sample is being organized in $(40,2 \%)$ of the organizations showing us the intensity of changes in the ambient influencing on the changes in workplaces' requirements but also on the growing need for continual education. From the aspect of human resources responsibility bearer: The additional training for the job they do in the organizations wherein the general manager takes over the responsibility for human resources had $(28,8 \%)$ of the examinees, did not have $(69,7 \%)$ and $(1,5 \%)$ of the examinees replied 'I do not know'; in the organizations where the human resources department takes on the responsibility for the additional training for the job they do had $(58,3 \%)$ of the examinees, did not have $(36,7 \%)$ and $5 \%$ of the examinees replied 'I do not know'; in the organizations wherein the human resources agency takes on the responsibility for human resources, the training for the job they do had (100\%) of the examinees; in the organizations wherein the legal department takes on the responsibility for human resources, the training for the job they do had (30\%), did not have (70\%) and no one of the examinees replied 'I do not know'; in the organizations wherein no one is responsible for human resources, the additional training for the job they do had $(27,3 \%)$ of the examinees, did not have (72,7\%) and no one of the examinees replied 'I do not know'; in the organizations where someone else takes on the responsibility for human resources, the additional training for the job they do had (30\%), did not have (70\%) and no one of the examinees replied 'I do not know'. It is evident that the greatest need for additional knowledge and skills is recognized in the organizations with human resources department and the least recognized in the organizations in which the general manager, legal department, no one or someone else takes care of the employees.

In the total sample, the employees needed in the greatest number of organizations $(46,7 \%)$ three months to master the knowledge and skills necessary for performing the job, six months $(14,2 \%)$, a year $(14,8 \%)$ and more $(8,3 \%)$. From the aspect of responsibility bearer for the employees: The time it took to the employees to master skills and knowledge for performing the jobs in the organizations wherein the general manager is responsible for human resources was three months $(42,4 \%)$, six months $(16,7 \%)$, a year $(13,6 \%)$, did not need additional time $(22,7 \%)$, and it took them more than a year $(4,5 \%)$; in the organizations wherein the human resources department is responsible for human resources, it took them three months $(53,3 \%)$, six months $(15 \%)$, a year $(18,3 \%)$, did not need any additional time (5\%), and it took them more than a year $(8,3 \%)$; in the organizations wherein the human resources agency is responsible for human resources, it took them three months (100\%); in the organizations wherein the legal department is responsible for human resources, it took them three months $(52,6 \%)$, six months $(5,3 \%)$, a year $(21,1 \%)$, did not need the additional time $(15,8 \%)$, and it took them more than a year $(5,3 \%)$; in the organizations wherein no one takes on the responsibility for human resources, it took them three months $(27,3 \%)$, six months $(18,2 \%)$, a year $(9,1 \%)$, did not need any additional time $(9,1 \%)$, and it took them more than a year $(36,4 \%)$; in the organizations wherein someone else takes on the responsibility for human resources, it took them three months $(40 \%)$, six months $(10 \%)$, a year $(0 \%)$, did not need any additional time $(40 \%)$ and it took them more than a year $(10 \%)$; The results of the research show that the employees need three months the most to master the needed knowledge and skills for doing the job, however, the result in the organizations in which no one is responsible for human resources is interesting because the examinees have stated that they 
needed more than a year to master the necessary skills and knowledge. It is obvious that in the organizations wherein no one takes care of the employees and thereby no one is in charge of managing the employees' knowledge, but everything happens uncontrollably, we have an expressed cost in decreased productivity because the employees spend too much time in mastering knowledge for doing the job.

From the aspect of the employees the focus was to investigate whether they have acknowledged the need in the past year for additional knowledge and skills. In the total sample the need for additional knowledge had (67,5\%) of the examinees showing us that the very employees notice the changes their job requires. From the aspect of bearer of responsibility for human resources, in the organizations wherein the general manager is in charge of human resources, the employees believe that they need additional knowledge $(56,1 \%)$, do not need $(42,4 \%)$ and $(1,5 \%)$ of the examinees replied 'I do not know'; in organizations wherein the human resources department is in charge of human resources, the employees believe that they need additional knowledge (81,7\%), do not need (18,3\%) and no one of the examinees replied 'I do not know'; in the organizations wherein the human resources agency is in charge of human resources, the employees believe that they do not need additional knowledge (100\%); in organizations wherein the legal department is in charge of human resources, the employees believe that they need additional knowledge (65\%), do not need (35\%) and none of the examinees replied 'I do not know'; in the organizations wherein the no one is in charge of human resources, the employees believe that they need additional knowledge (72,7\%), do not need (30\%) and no one of the examinees replied 'I do not know'; in the organizations wherein someone else is in charge of human resources, the employees believe that they need additional knowledge (80\%), do not need $(10 \%)$ and $(10 \%)$ of the examinees replied 'I do not know'; The greatest need for additional knowledge in the past year has been recognized by the employees in the organizations wherein the bearers of responsibility for human resources are human resources department and in the organizations wherein no one is in charge of the employees. If we compare the answers of the employees in the organizations wherein there is the human resources department to this question with the frequency of organizing additional training (most often in six months), it can compromise the selection of the trainings being organized for the employees.

The importance of training and development should be clear both to the organizations and to the employees. The organizations by training and development of the employees strengthen their human capital and the market competitiveness and the employees get the possibility of advancement and strengthening of their competitiveness on the labor market. The importance of the training in the total sample has been recognized by $(78,7 \%)$ of the examinees, $(7,1 \%)$ of the examinees thought that the developments were not important for their job and $(12,4 \%)$ of the examinees replied 'I do not know'. In the organizations wherein the general manager is responsible for human resources, the employees thought that the trainings and education were significant for their job (78,5\%), were not significant $(7,7 \%)$ and $13,8 \%$ of the examinees replied 'I do not know'; in the organizations wherein human resources department is responsible for human resources, the employees thought that the trainings and education were significant for their job $(84,7 \%)$, were not significant $(3,4 \%)$ and $11,9 \%$ of the examinees replied that they did not know; in the organizations wherein human resources agency is responsible for human resources, the employees thought that the trainings and education were significant for their job $(100 \%)$; in the organizations wherein legal department is responsible for human resources, the employees thought that the trainings and education were significant for their job $(78,9 \%)$, were not significant $(10,5 \%)$ and $18,2 \%$ of the examinees replied that they did not know; in the organizations 
wherein no one is responsible for human resources, the employees thought that the trainings and education were significant for their job $(63,6 \%)$, were not significant $(18,2 \%)$ and $(18,2 \%)$ of the examinees replied that they did not know; in the organizations wherein someone else is responsible for human resources, the employees thought that the trainings and education were significant for their job (80\%), were not significant $(10 \%)$ and $10 \%$ of the examinees replied that they did not know; In all the organizations regardless of the bearers of responsibility for human resources, the employees think that the trainings and specializations are important for their job. Somewhat less recognized importance of trainings is in the organizations wherein no one is responsible for human resources.

What is the benefit from the trainings and developments and to what extent an organization valorizes the investment into knowledge and sets it as the foundation of the advancement, namely, whether the training influences on advancement in the total sample $(59,2 \%)$ of the examinees replied that it did, $(27,2 \%)$ replied that it did not influence and $(12,4 \%)$ of the examinees replied that they did not know. From the aspect of human resources responsibility bearer: In the organizations wherein the general manager is responsible for human resources, the training and education influence on the possibility of advancement $(62,1 \%)$, do not influence $(27,3 \%)$ and $10,6 \%$ of the examinees replied that they did not know; in the organizations wherein human resources department is responsible for human resources, the training and education influence on the possibility of advancement (60\%), do not influence (25\%) and $15 \%$ of the examinees replied that they did not know; in the organizations wherein human resources agency is responsible for human resources, the training and education influence on the possibility of advancement $(100 \%)$; in the organizations wherein the legal department is responsible for human resources, the training and education influence on the possibility of advancement $(57,9 \%)$, do not influence $(21,1 \%)$ and $21,1 \%$ of the examinees replied that they did not know; in the organizations wherein no one is responsible for human resources, the training and education influence on the possibility of advancement (40\%), do not influence (50\%) and 10\% of the examinees replied that they did not know; in the organizations wherein someone else is responsible for human resources, the training and education influence on the possibility of advancement (60\%), do not influence $(40 \%)$ and none of the examinees replied that they did not know; As it was noticed, in most of the organizations the training and education influence on the possibility of advancement but the training is still not being organized to a significant extent $(33,8 \%)$, which leads us to the presupposition that training is left to the employees' free will.

As the criteria of advancement at the workplace in the total sample the examinees have isolated the work outputs $(41,5 \%)$, experience $(14,2 \%)$, years of service $(9,3 \%)$ and something else $(35 \%)$. From the aspect of human resources responsibility bearer: In the organizations wherein the general manager takes the responsibility for the employees, the promotion depends on experience $(13,6 \%)$, years of service $(12,1 \%)$, work outputs $(45,5 \%)$, something else $(40,9 \%)$; In the organizations wherein the human resources department takes the responsibility for the employees, the promotion depends on experience $(13,3 \%)$, years of service $(6,7 \%)$, work outputs $(48,3 \%)$, something else (38,3\%); In the organizations wherein human resources agency takes the responsibility for the employees, the promotion depends on work outputs $(100 \%)$; In the organizations wherein the legal department takes the responsibility for the employees, the promotion depends on experience $(27,8 \%)$, years of service $(22,2 \%)$, work outputs $(33,3 \%)$, something else $(27,8 \%)$; In the organizations wherein no one takes the responsibility for the employees, the promotion depends on experience $(27,3 \%)$, work outputs $(27,3 \%)$, something else $(54,5 \%)$; In the organizations wherein someone else takes the responsibility for the employees, the promotion depends 
on experience $(10 \%)$, years of service $(10 \%)$, work outputs $(60 \%)$, something else $(30 \%)$; It is noticeable that in the organizations the promotion depends on the work outputs and at the most in those in which no one is responsible for human resources. If the promotion depends to the greatest extent on work outputs and the work outputs are not accorded with earnings, undoubtedly the motivation of the employees for further advancement is brought into question. Also noticeable are the answers that the promotion depends on something else wherein the examinees have mostly stated the political determination, relations with the superiors, poltroon policy, family relations, etc.

If the employees perceive the advantages of training and development, namely if that would influence on the possibility of advancement within the organization, surely their motivation in investing into knowledge would be greater. According to the results of our research, in the total sample the employees are motivated to do the training $(34,3 \%)$, are not motivated $(37,3 \%)$ and $27,2 \%$ of the examinees replied that they did not know. Such results are not surprising having in mind who are the bearers of responsibility for human resources and that to the greatest extent the training is the issue of the very individual and not a defined need incorporated into the strategy of the organization itself. The organizations in which the general manager takes on the responsibility for human resources, the employees are motivated to attend the trainings $(31,3 \%)$, not motivated $(43,8 \%)$ and $25 \%$ of the examinees replied that they did not know; The organizations in which the human resources department takes on the responsibility for human resources, the employees are motivated to attend the trainings (41,7\%), not motivated (30\%) and 28,3\% of the examinees replied that they did not know; The organizations in which human resources agency takes on the responsibility for human resources, the employees are motivated to attend the trainings (100\%); The organizations in which the legal department takes on the responsibility for human resources, the employees are motivated to attend the trainings $(20 \%)$, are not motivated (50\%) and $30 \%$ of the examinees replied that they did not know; The organizations in which no one takes on the responsibility for human resources, the employees are motivated to attend the trainings (27,3\%), are not motivated $(45,5 \%)$ and $27,3 \%$ of the examinees replied that they did not know; The organizations in which someone else takes on the responsibility for human resources, the employees are motivated to attend the trainings (40\%), are not motivated (20\%) and $40 \%$ of the examinees replied that they did not know;

The training and specializations are a planned activity that should be adjusted to the strategic course of development and needs of the organizations. In the total sample the organizations organize the training and specializations according to the determined plans $(22,5 \%)$, the need $(36,7 \%)$, depending on the offer $(6,5 \%)$ and independently on anything $(26,6 \%)$. From the aspect of human resources responsibility bearer: The trainings and specializations in the organizations wherein the general manager takes on the responsibility for the employees are being organized according to the plans $(18,3 \%)$, need $(41,7 \%)$, depending on the offer $(10 \%)$, independently on anything (30\%); The trainings and specializations in the organizations wherein the human resources department takes on the responsibility for the employees are being organized according to the plans $(33,3 \%)$, as needed $(36,7 \%)$, depending on the offer $(5 \%)$, independently on anything (25\%); The trainings and specializations in the organizations wherein the human resources agency takes on the responsibility for the employees are being organized according to the plans $(100 \%)$; The trainings and specializations in the organizations wherein the legal department takes on the responsibility for the employees are being organized according to the plans $(15 \%)$, need (50\%), independently of anything (35\%); The trainings and specializations in the organizations wherein no one takes on the responsibility for the employees are being organized ac- 
cording to the plans $(14,3 \%)$, the need $(28,6 \%)$, depending on the offer $(14,3 \%)$, independently $(42,9)$; The trainings and specializations in the organizations wherein someone else takes on the responsibility for the employees are being organized according to the plans $(28,6 \%)$, need $(28,6 \%)$, depending on the offer $(14,3 \%)$, independently on anything $(28,6 \%)$; it can be noticed that in the organizations in which there is the human resources department, the trainings are organized to the greatest extent according to the plans and need, pointing to the positive role of this function in the company's operation. In the other organizations, the trainings are mainly organized according to the need, pointing to a random business operation and on corrective, instead of preventive actions which certainly necessitate greater expenses.

Whether development is a matter of an individual or a coordinated activity with the organization it has been checked by the question would they have the organization's support during the development. In the total sample $(53,8 \%)$ of the examinees replied that they would have the organization's support and even $(47,2 \%)$ of the examinees replied that they would not have the organization's support during the development which can be the consequence of undefined needs for skills and knowledge on behalf of the organization itself. From the aspect of human resources responsibility bearer: In the course of training and development in the organizations wherein responsible for the human resources is the general manager, the employees would have the organization's support $(55,6 \%)$ and would not have the organization's support $(44,4 \%)$; in the organizations wherein responsible for the human resources is the human resources department, the employees would have the organization's support (57,6\%) and would not have the organization's support $(42,4 \%)$; in the organizations wherein responsible for the human resources is the human resources agency, the employees would have the organization's support (100\%); in the organizations wherein responsible for the human resources is the legal department, the employees would have the organization's support $(63,2 \%)$ and would not have the organization's support $(36,8 \%)$; in the organizations wherein responsible for the human resources is no one, the employees would have the organization's support (72,7\%); in the organizations wherein responsible for the human resources is someone else, the employees would have the organization's support (55,6\%) and would not have the organization's support (44,4\%); The greatest support the employees have in the organizations wherein responsible for the employees is the legal department and the least in the organizations wherein no one takes the responsibility for human resources.

Whether the training and development are a matter of privilege and the chosen ones it has been investigated by the question whether all the employees have the possibility of training and development. In the total sample $33,1 \%$ of the examinees responded that they all had the possibility of training and development, $46,2 \%$ of the examinees responded that they did not have and $18,7 \%$ of the examinees replied that they did not know. In the organizations where the general manager is responsible for human resources all the employees have the possibility of training and development $(38,5 \%)$, all the employees do not have the possibility of training and development $(44,16 \%)$ and $16,9 \%$ of the examinees replied that they did not know; In the organizations where the human resources department is responsible for human resources all the employees have the possibility of training and development $(32,2 \%)$, all the employees do not have the possibility of training and development (47,5\%) and $20,3 \%$ of the examinees replied that they did not know; In the organizations where the human resources agency is responsible for human resources all the employees have the possibility of training and development $100 \%$; In the organizations where the legal department is responsible for human resources all the employees have the possibility of training and development $(21,1 \%)$, all the employees do not have 
the possibility of training and development (47,4\%) and $31,6 \%$ of the examinees replied that they did not know; In the organizations where no one is responsible for human resources all the employees have the possibility of training and development $(18,2 \%)$, all the employees do not have the possibility of training and development $(72,7 \%)$ and $9,1 \%$ of the examinees replied that they did not know; In the organizations where someone else is responsible for human resources all the employees have the possibility of training and development (50\%), all the employees do not have the possibility of training and development (40\%) and $10 \%$ of the examinees replied that they did not know. From the aspect of bearer of responsibility for human resources it is noticeable that there are the least the privileged ones in the organizations wherein someone else is responsible for the employees. It would be interesting to check what structure of the employees in the organizations has the possibility of development and what it depends on.

How much the organizations value the employees' development can be seen through the palette of privileges offered (short working time, possibility of choosing the shift, paying for the education expenses, no privilege, some other privilege). In the total sample they are short time of work (18,3\%), possibility of choosing the shift $(18,9 \%)$, paying for the education expenses $(25,4 \%)$, some other privilege $(8,3 \%)$ and no privileges $(12,4 \%)$; It can be noticed that the organizations offer various privileges for the employees that are developing, which can be additional motivation. From the aspect of human resources responsibility bearer the privileges for the training and development period in the organizations wherein the general manager takes care of the employees are short time (20,4\%), the possibility of shift choosing (33,3\%), paying for the education expenses $(18,5 \%)$, some other privilege (13\%) and there are no privileges $(14,8 \%)$; in the organizations wherein the human resources department takes care of the employees are short time $(25,9 \%)$, the possibility of shift choosing (14,8\%), paying for the education expenses $(42,6 \%)$, some other privilege $(9,3 \%)$ and there are no privileges $(7,4 \%)$; in the organizations wherein the human resources agency takes care of the employees it is the possibility of choosing the shift (100\%); in the organizations wherein the legal department takes care of the employees are short time $(31,3 \%)$, paying for the education expenses $(37,5 \%)$, some other privilege $(6,3 \%)$ and there are no privileges (25\%); in the organizations wherein no one takes care of the employees are the possibility of shift choosing (20\%), paying for the education expenses $(20 \%)$, and there are no privileges $(60 \%)$; in the organizations wherein someone else takes care of the employees are the possibility of shift choosing (40\%), paying for the education expenses $(30 \%)$, some other privilege (10\%) and there are no privileges $(20 \%)$;

The employees' satisfaction with the possibility of advancement and presenting of the ideas can greatly contribute to the lower fluctuation, higher motivation and creation of the culture in which any effort for the operations improvement is valued. By the possibilities of advancement and idea presenting in the investigated organizations in the total sample completely satisfied were $(28,4 \%)$ of the examinees, not satisfied $(22,5 \%)$ and even $(46,7 \%)$ of the examinees responded that they did not know. From the aspect of human resources responsibility bearer: The employed in the organizations in which the general manager takes care of the personnel, satisfied with the possibility of advancement and idea presentation are $(25,4 \%)$, dissatisfied $(46 \%)$ and $28,6 \%$ of the examinees replied 'I do not know'; The employees in the organizations in which the human resources department takes care of the personnel, satisfied with the possibility of advancement and idea presentation are (28,3\%), dissatisfied $(51,7 \%)$ and $20 \%$ of the examinees replied 'I do not know'; The employees in the organizations in which the human resources agency takes care of the personnel, satisfied with the possibility of advancement and idea presentation are 100(\%); The employees in the organizations in which the legal department takes 
care of the personnel, satisfied with the possibility of advancement and idea presentation are $(31,6 \%)$, dissatisfied $(57,9 \%)$ and $10,5 \%$ of the examinees replied 'I do not know'; The employees in the organizations in which no one takes care of the personnel, satisfied with the possibility of advancement and idea presentation are (36,4\%), dissatisfied (36,4\%) and 27,3\% of the examinees replied 'I do not know'; The employees in the organizations in which someone else takes care of the personnel, satisfied with the possibility of advancement and idea presentation are $(30 \%)$, dissatisfied (30\%) and $40 \%$ of the examinees replied 'I do not know'; It is surprising that the greater dissatisfaction with the system of advancement and the possibility of ideas presentation is expressed by the examinees in the organizations wherein the main bearers of the human resources activities are the human resources department and legal department.

The satisfaction of the employees with the organization as a whole can be a good indicator of the loyalty and degree of identifying with the organization. In the total sample the employees in the investigated organizations are completely satisfied $(30,4 \%)$, dissatisfied $(19,6 \%)$ and even $(50 \%)$ of the examinees replied 'I do not know'. From the aspect of human resources responsibility bearer: In the organizations in which the general manager takes care of the human resources the employees are satisfied with the organization as a whole $(28,8 \%)$, dissatisfied $(16,7 \%)$ and 54,5 $\%$ of the examinees replied 'I do not know'; In the organizations in which the human resources department takes care of the human resources the employees are satisfied with the organization as a whole (38,3\%), dissatisfied (15\%) and $46,7 \%$ of the examinees replied 'I do not know'; In the organizations in which the human resources agency takes care of the human resources the employees are satisfied with the organization as a whole (100\%); In the organizations in which the legal department takes care of the human resources the employees are satisfied with the organization as a whole $(15,8 \%)$, dissatisfied $(36,8 \%)$ and $47,4 \%$ of the examinees replied 'I do not know'; In the organizations in which no one takes care of the human resources the employees are satisfied with the organization as a whole $(9,1 \%)$, dissatisfied $(27,3 \%)$ and $63,6 \%$ of the examinees replied 'I do not know'; In the organizations in which someone else takes care of the human resources the employees are satisfied with the organization as a whole (40\%), dissatisfied (30\%) and $30 \%$ of the examinees replied 'I do not know'; In the total sample it can be notice that a very small number of the employees are satisfied with the organization and that a great number of the examinees replied 'I do not know'. The greatest dissatisfaction the examinees expressed in the organizations with legal department and in the organizations in which no one takes care of the employees and the least satisfaction was expressed by the examinees in the organizations with human resources department.

Whether the employees think that their capacities have been completely utilized one of the goals was to investigate by the question what is their degree of knowledge and skills utilization at work. In the total sample the employees use up to $25 \%$ of their knowledge $(14,8 \%)$, up to $(50 \%)$ of their knowledge (36,7\%), up to $75 \%$ of their knowledge $(32,5 \%)$ and up to $100 \%$ of their knowledge; from the aspect of responsibility bearer for human resources: In the organizations wherein responsible for human resources is the general manager the employees use up to $25 \%$ of their knowledge $(13,8 \%)$, up to $50 \%$ of their knowledge $(33,8 \%)$, up to $75 \%$ of their knowledge $(32,3 \%)$ and up to $100 \%$ of their knowledge (20\%); In the organizations wherein responsible for human resources is the human resources department the employees use up to $25 \%$ of their knowledge (20,3\%), up to $50 \%$ of their knowledge (39\%), up to $75 \%$ of their knowledge $(30,5 \%)$ and up to $100 \%$ of their knowledge (10,2\%); In the organizations wherein responsible for human resources is the agency for human resources the employees use up to $75 \%$ of their knowledge $(100 \%)$; In the organizations wherein responsible for human resources is the legal department 
the employees use up to $25 \%$ of their knowledge $(11,1 \%)$, up to $50 \%$ of their knowledge $(44,4 \%)$, up to $75 \%$ of their knowledge $(44,4 \%)$ and none of the examinees thinks that his degree of the knowledge utilization is $100 \%$; In the organizations wherein no one is responsible for human resources the employees use up to $25 \%$ of their knowledge $(9,1 \%)$, up to $50 \%$ of their knowledge (54,5\%), up to $75 \%$ of their knowledge $(27,3 \%)$ and up to $100 \%$ of their knowledge $(9,1 \%)$; In the organizations wherein someone else is responsible for human resources the employees use up to $25 \%$ of their knowledge $(10 \%)$, up to $50 \%$ of their knowledge $(20 \%)$, up to $75 \%$ of their knowledge (40\%) and up to $100 \%$ of their knowledge (10\%); It can be noticed that regardless of the bearer of responsibility for human resources in the organization, a very small number of the examinees thinks that their knowledge, abilities and potentials are completely utilized.

Permanent development of knowledge becomes the requirement of every workplace nowadays. In the examined organizations in the total sample, $(53,3 \%)$ of the examinees thinks that the permanent development of knowledge is necessary for them, $(35,3 \%)$ regards that they do not need it and $(11,4 \%)$ of the examinees replied 'I do not know'. From the aspect of human resources responsibility bearer: In the organizations wherein the general manager is responsible for human resources, the employees believe that the permanent development of knowledge for the job they do is necessary for them $(52,3 \%)$, that it is not necessary for them $(38,5 \%)$ and $9,2 \%$ of the examinees replied 'I do not know'; In the organizations wherein the human resources department is responsible for the human resources, the employees believe that the permanent development of knowledge for the job they do is necessary for them (55\%), that it is not necessary for them (30\%) and $15 \%$ of the examinees replied 'I do not know'; In the organizations wherein the human resources agency is responsible for the human resources, the employees believe that the permanent development of knowledge for the job they do is necessary for them (100\%); In the organizations wherein the legal department is responsible for the human resources, the employees believe that the permanent development of knowledge for the job they do is necessary for them (52,6\%), that it is not necessary for them $(36,8 \%)$ and $10,5 \%$ of the examinees replied 'I do not know'; In the organizations wherein no one is responsible for the human resources, the employees believe that the permanent development of knowledge for the job they do is necessary for them $(45,5 \%)$, that it is not necessary for them $(36,4 \%)$ and $18,2 \%$ of the examinees replied ' $I$ do not know'; In the organizations wherein someone else is responsible for the human resources, the employees believe that the permanent development of knowledge for the job they do is necessary for them (50\%), that it is not necessary for them $(50 \%)$ and none of the examinees replied 'I do not know'; In most of the organizations regardless of the bearer of responsibility for human resources, the employees believe that the permanent development of knowledge is necessary for them. Organizing the trainings according to a plan (which is not the case in our organizations) would be one of the prerequisites of better business operations.

As it was already stated in the theoretical part of the paper, there are various models of training and education. In the investigated organizations, in the total sample present are briefing $(12,2 \%)$, the employees' orientation (5,6\%), the profile addition $(3,6 \%)$, training period $(21,9 \%)$, professional and technical training (23\%), additional education (12,8\%) and rotations and provisional transfers (20,9\%). From the aspect of human resources responsibility bearer from the models of education in the organizations in which responsible for human resources is the general manager, present are briefing $(13,3 \%)$, the employees' orientation $(8,3 \%)$, the profile addition $(5 \%)$, training period (25\%), professional and technical training $(31,7 \%)$, additional education $(18,3 \%)$ and rotations and provisional transfers $(21,7 \%)$; in the organizations in which responsible for human resources is the human resources department, present are briefing $(14,3 \%)$, the employees' orientation $(7,1 \%)$, 
the profile addition (7,1\%), training period (30,4\%), professional and technical training $(35,7 \%)$, additional education (19,6\%) and rotations and provisional transfers $(26,8 \%)$; in the organizations in which responsible for human resources is the human resources agency, present is professional and technical training $(100 \%)$; in the organizations in which responsible for human resources is the legal department, present are briefing (20\%), training period (35\%), professional and technical training (10\%), additional education (15\%) and rotations and provisional transfers $(45 \%)$; in the organizations in which no one is responsible for human resources, present are briefing (20\%), training period (40\%), professional and technical training (20\%), and rotations and provisional transfers (20\%); in the organizations in which someone else is responsible for human resources, present are briefing (37,5\%), the employees' orientation (25\%), training period (25\%), professional and technical training $(12,5 \%)$, and rotations and provisional transfers $(37,5 \%)$; It can be noticed that in relation to the bearers of responsibility for human resources there is the difference in the presence of education model. What can be singled out as interesting herein are the results showing a very small presence of the employees' orientation regardless of all the advantages it provides.

As the main barriers to the maximum utilization of their potentials and knowledge the employees, in the total sample, perceive the inadequate equipment $(9,8 \%)$, bad collective $(6,1 \%)$, bad organization of work (30,4\%), burden with unskilled work $(18,2 \%)$, insufficient support of the associates $(13,3 \%)$ and insufficient concern on the company's development $(22,4 \%)$. From the aspect of human resources responsibility bearer: In the organizations in which the general manager is responsible for the employees, they believe that it is the inadequate equipment $(15,5 \%)$, bad collective $(12,1 \%)$, bad organization of labor $(46,6 \%)$, burden with unskilled work (31\%), insufficient support of the associates $(15,5 \%)$ and insufficient concern on the company's development (39,7\%); the employees for whom the human resources department is responsible believe that it is the inadequate equipment $(17,6 \%)$, bad collective $(5,9 \%)$, bad organization of labor (33,3\%), burden with unskilled work $(19,6 \%)$, insufficient support of the associates $(23,5 \%)$ and insufficient concern on the company's development $(33,3 \%)$; the employees for whom the legal department is responsible believe that it is the inadequate equipment $(10,5 \%)$, bad collective $(10,5 \%)$, bad organization of labor $(52,6 \%)$, burden with unskilled work $(31,6 \%)$, insufficient support of the associates $(21,1 \%)$ and insufficient concern on the company's development $(15,8 \%)$; the employees for whom no one is responsible believe that it is the bad collective $(10 \%)$, bad organization of labor (70\%), burden with unskilled work (30\%), insufficient support of the associates (10\%) and insufficient concern on the company's development (40\%); the employees for whom someone else is responsible believe that it is the inadequate equipment $(16,7 \%)$, bad organization of labor $(66,7 \%)$, burden with unskilled work $(16,7 \%)$, insufficient support of the associates $(33,3 \%)$ and insufficient concern on the company's development $(16,7 \%)$;

\section{CONCLUSION}

According to the shown results of the research, as well as to the determined differences, it can be isolated some characteristics on the trainings and education of the employees in the organization in relation to the various bearers of responsibility for human resources and therewith confirm the main hypothesis that there are differences in trainings and education of the employees in relation to different bearers of the activities:

The organizations in which the main bearer of human resources management function is the general manager are characterized by the following: There are workplaces descriptions $(74,2 \%)$, descriptions of work corresponding to what the employees do $(66,2 \%)$, the formal processes of 
performance estimation do not exist (47\%), the performance estimation is held randomly (29,7\%) and not held at all $(31,3 \%)$, the performance is estimated by the sector manager $(41,5 \%)$, direct superior $(44,6 \%)$, the reward system does not exist (41,5\%), the earnings are not in accordance to the work outputs $(50 \%)$, the training and specializations are not being organized $(45,5 \%)$, have never had the training (53\%) of the examinees; the training at the employment did not have $(61,5 \%)$, the additional training for the existing jobs is not being organized (69,7\%), three months is the period needed for mastering knowledge and skills necessary for performance of the job $(42,4 \%)$, the employees think that the trainings were necessary to them in the past year in order to better master their job $(56,1 \%)$, the employees believe that the developments are significant for their job (78,5\%), the trainings and education influence on the possibility of advancement $(62,1 \%)$, the promotion depends on the work outputs $(45,5 \%)$ and something else $(0,9 \%)$; the employees are not motivated $(43,8 \%)$ to attend the courses, the trainings are organized according to the need $(41,7 \%)$ and are organized independently on anything $(30 \%)$; the organization's support during the development would have $(55,6 \%)$ and would not have $(44,4 \%)$ of the employees; all the employees do not have the possibility of training and development $(44,16 \%)$; of the privileges during the development the most present are short time $(20,4 \%)$, the possibility of choosing the shift (33,3\%); the employees are not satisfied with (46\%) the possibilities of the advancements and presenting the ideas, the employees utilize only up to $50 \%$ of their knowledge $(33,8 \%)$, the employees think that the permanent development of knowledge is necessary to them for the job they do (52,3\%); of the models of training and education the most present are the training period (25\%), professional and technical training $(31,7 \%)$ and rotations and provisional transfers $(21,7 \%)$; the barriers in the maximum utilization of knowledge are bad organization of labor $(46,6 \%)$, burden with unskilled work (31\%) and insufficient concern on the company's development $(39,7 \%)$;

The organizations in which the main bearer of human resources management function is the human resources department are characterized by the following: there are workplaces descriptions $(88,3 \%)$, descriptions of work corresponding to what the employees do $(58,3 \%)$, the formal processes of performance estimation exist $(75 \%)$, the performance estimation is held in three months $(27,6 \%)$, a year $(20,7 \%)$, randomly $(29,3 \%)$, the performance is estimated by the sector manager $(36,7 \%)$, direct superior $(58,3 \%)$, the employees are partially satisfied with the rewarding system $(38,3 \%)$, the earnings are in accordance to the work outputs $(43,3 \%)$, the trainings are being organized $(80 \%)$, they have had the training in the last six months $(37,7 \%)$, the training at the employment had $(64,4 \%)$ of the examinees, the additional training for the job they do had $(58,3 \%)$ of the employees, for mastering knowledge and skills necessary for performance of the job it took them three months $(53,3 \%)$, the employees think that the trainings are necessary to them $(81,7 \%)$, that they are significant for their job $(84,7 \%)$, the trainings and education influence on the possibility of advancement (60\%), the promotion depends on the work outputs $(48,3 \%)$ and something else $(38,3 \%)$; the employees are motivated $(41,7 \%)$ to attend the courses, the trainings are organized according to the plans $(33,3 \%)$, to the need $(36,7 \%)$; the organization's support during the development would have (57,6\%); not all the employees have the possibility of training and development (47,5\%), of the privileges during the development the most present are short time $(25,9 \%)$ and paying for the education expenses $(42,6 \%)$, the employees are not satisfied with $(51,7 \%)$ the possibilities of the advancements and presenting the ideas, the employees are satisfied with the organization as a whole (38,3\%) and (46,7\%) of the employees replied 'I do not know'; the employees utilize the most up to $50 \%$ of their knowledge (39\%) and up to (75\%) of their knowledge (30,5\%), the employees think that the permanent development of knowledge is necessary to them for the job they do (55\%), of the models of training and education the most present are the training period $(30,4 \%)$, professional and technical training $(35,7 \%)$ and rotations 
and provisional transfers $(26,8 \%)$; the barriers in the maximum utilization of knowledge are bad organization of labor $(33,3 \%)$, insufficient support of the associates $(23,5 \%)$ and insufficient concern on the company's development $(33,3 \%)$;

The organizations in which the main bearer of human resources management function is the legal department are characterized by the following: The workplaces' descriptions exist (85\%); descriptions of work correspond to what the employees do $(65 \%)$; the formal processes of performance estimation do not exist (65\%); the performance estimation is held randomly $(42,1 \%)$ and not held at all (26,3\%); the performance is estimated by the sector manager $(25 \%)$ and direct superior $(70 \%)$, the rewarding system does not exist (40\%), the earnings are not in accordance to the work outputs $(80 \%)$, the trainings are being organized $(55 \%)$, the trainings have been organized in the past three years $(36,8 \%)$ and have never been organized $(36,8 \%)$; the training at the employment did not have $(60 \%)$ of the employees, the training for the jobs they do did not have $(70 \%)$ of the employees; the period needed for mastering knowledge and skills necessary for performance of the job is three months $(52,6 \%)$, the employees think that the trainings are necessary to them for the better job performance $(65 \%)$, that they are significant for their job (78,9\%), the trainings and education influence on the possibility of advancement $(57,9 \%)$, the promotion depends on the experience $(27,8 \%)$, years of service $(22,2 \%)$, work outputs $(33,3 \%)$ and something else $(27,8 \%)$; the employees are not motivated (50\%) to attend the courses, the trainings are organized according to the need (50\%) and are organized independently on anything (35\%); the organization's support during the development would have $(63,2 \%)$; all the employees do not have the possibility of training and development $(47,4 \%)$, of the privileges during the development the most present are short time $(31,3 \%)$ and paying for the education expenses (37,5\%), the employees are not satisfied with the possibilities of the advancements and presenting the ideas $(57,9 \%)$, the employees are satisfied with the organization as a whole $(36,8 \%)$ and $(47,4 \%)$ of the examinees replied 'I do not know'; the employees utilize only up to $50 \%$ of their knowledge $(44,4 \%)$ and up to $75 \%$ of their knowledge $(44,4 \%)$, the employees think that the permanent development of knowledge is necessary to them for the job they do $(52,6 \%)$, of the models of training and education the most present are: training period (35\%) and rotations and provisional transfers (45\%); as the barriers in the maximum utilization of knowledge they perceive: bad organization of labor $(52,6 \%)$ and burden with unskilled works $(31,6 \%)$;

The organizations in which no one is the main bearer are characterized by the following: there are workplaces descriptions (63,6\%); descriptions of work corresponding to what the employees do $(54,5 \%)$, the formal processes of performance estimation do not exist $(90,9 \%)$; the performance estimation is not held at all $(63,6 \%)$; the performance is estimated by the direct superior $(63,6 \%)$; the employees are dissatisfied with the rewarding system $(36,4 \%)$ and $(45,5 \%)$ of the examinees replied that that there was no reward system; the earnings are in accordance to the work outputs $(72,7 \%)$, the trainings are not being organized (72,7\%); for the job they do they have never had the additional training $(63,6 \%)$, the training at the employment had $(60 \%)$ of the employees; for mastering knowledge and skills necessary for performance of the job the employees took more than a year $(36,4 \%)$; the employees think that the trainings are necessary for their job $(63,6 \%)$; the trainings and education do not influence on the possibility of advancement (50\%), the promotion depends on something else (54,5\%); the employees are not motivated to attend the courses $(45,5 \%)$, the trainings are organized independently from anything $(42,9 \%)$; during the training and development they would not have the organization's support (72,7\%); not all the employees have the possibility of training and development (72,7\%), during the development the employees have no privileges $(60 \%)$, the employees are not satisfied with the possibilities of the advance- 
ments and presenting the ideas (36,4\%); the employees are dissatisfied with the organization as a whole (27,3\%) and 63,6\% of the employees replied 'I do not know'; the employees utilize the most up to $50 \%$ of their knowledge $(54,5 \%)$; the employees think that the permanent development of knowledge is necessary to them for the job they do (45,5\%), that it is not necessary $(36,4 \%)$; of the models of training and education the most present is the training period (40\%); as the main barriers in the maximum utilization of knowledge and potentials the employees perceive: bad organization of labor (70\%) and insufficient concern on the company's development (40\%);

The organizations in which the main bearer is someone else are characterized by the following: The workplaces descriptions do not exist (50\%); descriptions of work corresponding to what the employees do (70\%); the formal processes of performance estimation do not exist $(70 \%)$; the performance estimation is held randomly (30\%) and is not held at all (40\%); the performance is estimated by the direct superior $(44,4 \%)$ and someone else $(33,3 \%)$; the employees are partially satisfied (30\%) with the reward system but also $30 \%$ of the employees replied that the rewarding system did not exist; the earning is not in accordance with the work outputs $(60 \%)$; the trainings are not being organized (60\%); the employees have never had the training (50\%); the training at the employment did not have (60\%) of the employees; the additional training for the job they do did not have (70\%) of the employees; for mastering the knowledge and skills necessary for the job performance three months have been necessary to the employees $(40 \%)$ and did not need any additional time (40\%); the employees believe that the trainings are necessary for their job $(80 \%)$; the trainings and education influence on the possibility of advancement $(60 \%)$; the promotion depends on the work outputs $(60 \%)$ and something else (30\%); the trainings are organized independently on anything $(28,6 \%)$; the employees would have the organization's support during the training (55,6\%); not all the employees have the possibility of training and development (40\%); of the privileges during the training and development the most present are choosing the shift (40\%) and paying for the education expenses (30\%); the employees are not satisfied with the possibilities of the advancements and presenting the ideas (30\%) and $40 \%$ of the examinees replied 'I do not know'; the employees are dissatisfied with the organization as a whole (30\%) and $30 \%$ of the examinees replied 'I do not know'; the employees utilize up to $50 \%$ of their knowledge $(20 \%)$ and up to $75 \%$ of their knowledge (40\%); the employees think that the permanent development of knowledge is not necessary to them for the job they do (50\%); of the models of education the most used are: briefing (37,5\%) and rotations and provisional transfers $(37,5 \%)$; as the main barriers in the maximum utilization of their knowledge and potentials the employees perceive: bad organization of labor $(66,7 \%)$, insufficient support of the associates $(33,3 \%)$;

For the purpose of increasing an organization's competitiveness in service sector it is necessary to devote to the most relevant resource today, to the employees. As the research shows, the necessary premise is the existence of the human resources department, which too great number of organizations still does not have. Undoubtedly, in the organizations in which there is the human resources department the employees have a much greater level of motivation, satisfaction with the job and organization and a clearer image on the necessity, importance and valuing of the continual education as the basis of an individual and organizational development and competitiveness. However, as shown by the research, also in the organizations in which there is the human resources department there are problems of insufficiently accorded descriptions of works with the employees' jobs, dissatisfaction with the reward system, non-accordance of the earnings with the work outputs, etc., pointing us that this department and its role in the organizations is still at the origination and that further development in improvement of all the activities of the human resources management process is necessary. 


\section{REFERENCES}

Ahmad, S., Schroeder, R. (2003): The impact of human resource management practices on operational performance: Recognizing country and industry differences, Journal of Operations Management, 21(1), 19-43.

Akhtar, S., Ding, D. Z., Ge, G. L. (2008): Strategic HRM practices and their impact on company performance in Chinese enterprises, Human Resource Management,47(1), 15-62.

Armstrong, M., (2008): Strategic Human Resource Management-A Guide to Action,4 ed. Kogan Page Limited, London

Baird, L., Meshoulam, I., (1988): Managing two fits of strategic human resource management. Academy of Management Review, 13(1), 116-128

Carroll, S. J., Paine, F. T., Ivancevich, J. J., (1972): The relative Effectiveness of Training Methods- Experts Opinion Research, Personnel Psychology

Cascio, W.F. (1991): „Costing human resources: The financial impact of behavior on organizations" (3rd ed.) Boston: PWS - Kent.

Dessler, G., (2002): Framework of Human Resource Management, 2nd Edition, The Dryden Press, Prentice Hall, New Jersey

Drucker, P., (1954): The practice of management, Butterworth-Heinemann

Dyer, W. G., (1999): Training Human Resources Champions for twenty first century, Human Resources Management, 38, 119-124

Hansson, B., (2001): Marketable Human Capital Investments: An Empirical Study of Employer - Sponsored Training, Stockholm: School of Business

Hansson, B., (2005): Company based determinants of training and the impact of training on company performance: results from an International HRM survey, The Institute for Employee and Corporate Development, Uppsala University

Jackson, S. E., Schuler, R. S. (1995): Understanding human resource management in the context of organizations and their environments. Annual Review of Psychology, 46, 237-264.

Katz, R. L., (1974): Skills of an effective administrator, Harvard Business Review, 52(5), 90-120

Kepes, S., Delery, J. E., (2007): HRM systems and the problem of internal fit, In P. C. Boxall, J. Purcelland, Wright, P. M. (Eds.). The Oxford handbook of human resource management. Oxford [et al.]: Oxford Univ. Press, pp. 385-404.

Legnick-Hall, C. A., Legnick-Hall, M.L., (1990): Interactive HRM and strategic planning, Quorum books, Westport, Mahoney, T and Deckop, J. R., (1986): Evolution of concept and practice in personnel

Lepak, D. P., Snell, S. A., (2002): Examining the human resource architecture: The relationships among human capital, employment, and human resource configurations. Journal of Management, 28(4), 517-543.

Miles, R. E., Snow, C. C., (1984):” Fit, Failure and The Hall of Fame.” California Management Review, 26(3), 10-28.

Milkić Bogićević, B., (2006): (Human Resources Management, The Center for Publishing activities of the Faculty of economics); Menadžment ljudskih resursa, Centar za izdavačku delatnost Ekonomskog fakulteta: Čugura Print, Beograd

Noe, E. R., (2001): Employee Training and Development, $2^{\text {nd }}$ edition, Mc Graw-Hill, Higher Education

Noe, R. A., Hollenbeck, J. R., Gerhart, B., Wright, P. W., (2000): Human Resources management: gaining a competitive advantage (3rd ed.), Boston, McGraw-Hill

Robinns, S. P., Coulter, M., (2005): Menadžment, Data status, 
Rothstein, H. R., (1999): Recruitment and selection: benchmarking at the millennium, In A.I. Kraut, A.K. Korman (eds.), Evolving practices in human resources management (pp. 170182), San Francisco, CA, Jossy-Bass

Schuler, S. J., Rivero J. C. R., (1989): „Organizational Characteristics as Predictor of Personnel Practices. Personnel Psychology 42(4): 727-86

Schuler, R. S., Jackson, S. E., (1987): Linking competitive strategies with human resource management practices, Academy of Management Executive, 1(3), 207-219.

Schuler, R. S., (1995): Managing Human Resources, $5^{\text {th }}$ ed, West Publishing Company,

Senge, P., (1990): The Fifth Discipline: The Art and Practice of the Learning Organization, Doubleday

Shih, H. A., Chiang, Y. H., Hsu, C. C., (2006): Can high performance work systems really lead to better performance? International Journal of Manpower, 27(8), 741-763.

Šiber, F. B., (1999): Menadžment ljudskih potencijala, Golden Marketing, Zagreb); Menadžment ljudskih potencijala, Golden marketing, Zagreb

Stewart, T. (1997): Intellectual Capital. New York: Currency, Doubleday

Tamkin, P., Giles L., Campbell M., Hillage, J., (2004): Skills Pay: The contribution of skills to business success, Institute for Employment Studies

Wright, P.M, McMahan, G. C, MC-Williams (1994): „Human Resource and sustained competitive advantage: A Resource Based perspective", International journal of Human Resource Management 5(2) 30 1-26.

Wright, P. M., Barney, J. B., (1998): On becoming strategic partner: The role of human resources in gaining competitive advantage, Human Resources Management Journal, vol. 37., issue 1., p.31-46

Wright, P. M., McMahan, G.C., Snell, S.A., Gerhart, B. (2001): Comparing Line and HR Executives' Perceptions of HR Effectiveness: Services, Roles, and Contributions. Human Resource Management, 30, p. 111-123.

Wright, P. M., McMahan, G. C., Snell, S. A., Gerhart, B. A., (1998): Strategic human resources management: Building human capital and organizational capability, Technical report sponsored by the strategic human resources foundation and the human resources planning society

Wright, P. M., Smart, D. L., McMahan, G. C. (1995): Matches Between Human Resources and Strategy Among NCAA Basketball Teams. Academy of Management Journal, vol. 38, p. 1052-1074. 